\title{
Erratum to: Change in test-taking motivation and its relationship to test performance in low-stakes assessments
}

\author{
Christiane Penk ${ }^{1} \cdot$ Dirk Richter $^{2}$
}

Published online: 19 November 2016

(C) Springer Science+Business Media New York 2016

\section{Erratum to: Educ Asse Eval Acc \\ DOI 10.1007/s11092-016-9248-7}

In the original version of this article, there is a typographical error in the acknowledgements section. The name should be "Sara J. Finney" and not "Sara J. Fin ney". Also, in the Appendix section, the columns in Table 5 were switched. Kindly see below correct Table 5. The original article was corrected.

The online version of the original article can be found at http://dx.doi.org/10.1007/s11092-016-9248-7.

Christiane Penk

penk@dipf.de

1 German Institute for International Educational Research (DIPF), Warschauer Str. 34-38, 10243 Berlin, Germany

2 University of Potsdam, Potsdam, Germany \& Institute for Educational Quality Improvement (IQB), Berlin, Germany 
Table 5 Correlations of the growth parameters for effort, importance, probability of success, and self-concept in mathematics: the indirect effects and non-significant effects for model 2

\begin{tabular}{|c|c|c|c|}
\hline Correlations & beta & $(S E)$ & \\
\hline Effort intercept with effort slope & $-0.23 *$ & $(0.00)$ & \\
\hline Probability of success intercept with probability of success slope & 0.03 & $(0.00)$ & \\
\hline Importance intercept with importance slope & $-0.08 *$ & $(0.00)$ & \\
\hline Importance intercept with probability of success intercept & -0.02 & $(0.00)$ & \\
\hline Importance slope with probability of success slope & $0.34 *$ & $(0.00)$ & \\
\hline Effort intercept with self-concept in mathematics & 0.05 & $(0.01)$ & \\
\hline Effort slope with self-concept in mathematics & -0.03 & $(0.00)$ & \\
\hline Importance intercept with self-concept in mathematics & $0.09 *$ & $(0.01)$ & \\
\hline Importance slope with self-concept in mathematics & -0.01 & $(0.00)$ & \\
\hline Indirect effects & $b$ & $(S E)$ & beta \\
\hline Performance on importance intercept via effort intercept & $0.25 *$ & $(0.03)$ & 0.13 \\
\hline Performance on importance slope via effort slope & 0.10 & $(0.13)$ & 0.02 \\
\hline Performance on probability of success intercept via effort intercept & $0.10^{*}$ & $(0.01)$ & 0.03 \\
\hline Performance on probability of success slope via effort slope & 0.04 & $(0.05)$ & 0.01 \\
\hline Non-significant effects & $b$ & $(S E)$ & beta \\
\hline Performance on importance intercept & -0.09 & $(0.04)$ & -0.05 \\
\hline Performance on importance slope & 0.06 & $(0.18)$ & 0.01 \\
\hline Performance on effort slope & 0.16 & $(0.20)$ & 0.03 \\
\hline Probability of success slope on self-concept in mathematics & 0.00 & $(0.01)$ & -0.02 \\
\hline
\end{tabular}

$b$ unstandardized regression coefficient, $S E$ standard error, beta standardized regression coefficient $* p<.001$ 